\title{
Islanded Parascapular Flap: An Above Elbow Stump Cover
}

Leena Jain*

Department of Plastic, Reconstructive and Microsurgery, Lilavati Hospital, Mumbai, Maharashtra, India

*Corresponding author: Leena Jain, Clinical Associate, Department of Plastic, Reconstructive and Microsurgery, Lilavati Hospital, Mumbai, Maharashtra, India, E-mail: link.jain@gmail.com

Received date: January 19, 2015, Accepted date: March 13, 2015, Published date: March 17, 2015

Copyright: (c) 2015 Leena J. This is an open-access article distributed under the terms of the Creative Commons Attribution License, which permits unrestricted use, distribution, and reproduction in any medium, provided the original author and source are credited.

\begin{abstract}
Introduction: In the management of amputation stumps, surgical endeavour is to provide an ideal stump, over which a well-fitting prosthesis maybe given. Moving on from the conventional workhorse flap cover of latissimus dorsi muscle or myocutaneous flap, free fasciocutaneous flaps offer several advantages. With the advent of perforator flaps, there seems to be a resurgence of islanded regional flaps providing a better tissue match while reducing the donor site morbidity.

Materials and Methods: The successful use of a parascapular fasciocutaneous flap to cover an above-elbow amputation stump with exposed bone is described in a patient with post traumatic above elbow amputation attributable to a long pedicle and its eccentric location. With no further shortening of the bone length, the stump was covered with robust tissue of good match with primary closure of donor site while preserving the latissimus dorsi muscle. This was carried out in Department of Plastic Surgery, Victoria Hospital, Bangalore Medical College and Research Centre, Bangalore.
\end{abstract}

Conclusion: The islanded parascapular flap is a good option for above elbow stump cover reaching up to the distal third of the arm providing robust tissue of excellent match without any donor site morbidity. Also we believe that this application of islanded parascapular flap for above elbow amputation stumps has not been described in the past.

Keywords: Fasciocutaneous flap; Islanded; Eccentric pedicle

\section{Case Report}

Above elbow amputation can be the devastating long term morbidity of electrical burns or trauma. Besides loss of functional part of the upper limb, a short stump hampers the anchorage of prosthesis.

Thus, the emphasis on preservation of as much as possible stump length and its adequate cover to enable a pain free usage of the prosthesis.

We describe the islanded parascapular flap cover for above elbow stump- a robust fasciocutaneous flap from the trunk with an adequate pedicle length.

25 year old male patient presented with a post-traumatic right above elbow stump raw area with exposed humerus, about 20 days after the accident.

The stump length was about $13 \mathrm{cms}$ from the tip of the acromion to bone end and $10 \mathrm{cms}$ from the axilla to the bone end along the posterior axillary fold. The defect size was $14 \times 10 \mathrm{cms}$.Perforators of thoracodorsal artery and circumflex scapular branch were marked according to the Doppler signals with the patient in left lateral position (Figure 1)

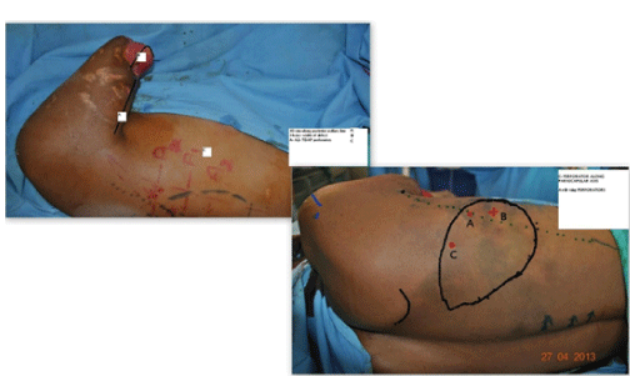

Figure 1: Right above elbow stump with exposed bone with markings of the skin paddle with the shown perforators.

A superolateral incision was placed towards the vertical cutaneous branch of circumflex scapular artery. Having identified a perforator and tracing it to the triangular space, the rest of the flap was marked. The flap was marked differently from the usual parascapular flap pattern as shown. The pedicle entered along the middle of the superior border of the flap; this eccentric location allowed for tension free reach.

A pedicle length of about $10 \mathrm{cms}$ was available as the flap was based eccentrically. The horizontal branch was then ligated and this allowed a further mobilization of 2-3cms (Figures 2 and 3). 
Page 2 of 3

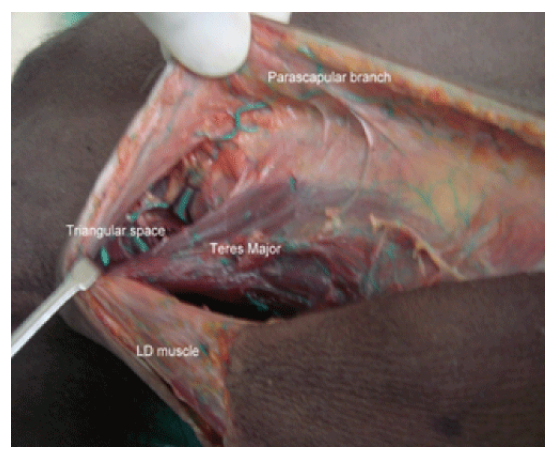

Figure 2: Cadaveric dissection showing the parascapular branch course from the triangular space distally

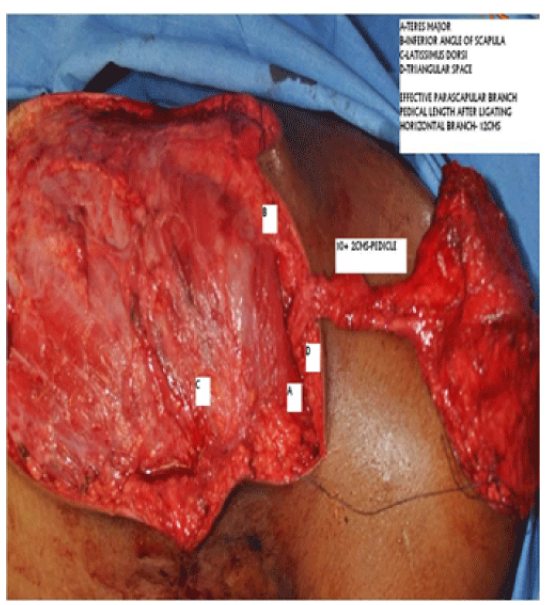

Figure 3: Retrograde flap dissection after perforator identification.

This facilitated tunneling the flap into the defect along the posterior axillary fold in the subcutaneous plane, which was the shortest route.

Length of the flap being $14 \mathrm{cms}$ facilitated closure of the entire defect with provision of a convex surface over the stump. Primary closure of the donor site was done over drains and the post-operative period was uneventful (Figure 4). There were no complications with the flap or the donor site.

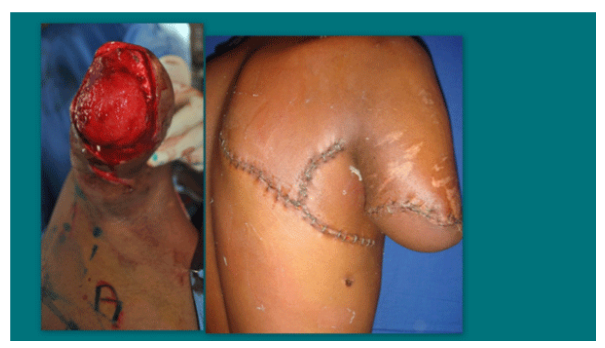

Figure 4: Pre-operative defect with completed flap inset with donor site closure.
An ideal stump is the one that has sufficient length, a stable, wellpadded and sensate soft tissue cover with a non-adherent painless scar. Despite the availability of better prosthesis, the cardinal rule is to preserve all possible length [1].

Historically, many treatment options have been proposed for elbow coverage including primary closure, skin graft, local flaps (v-y advancement), pedicled flaps, and free flaps;as per the reconstructive ladder [2].

Distant pedicled flaps from the chest or abdominal wall were used for lower arm and elbow coverage while regional pedicled flap of choice has been the latissimus dorsi [3]. Free flap commonly used is the anterolateral thigh flap providing a robust cover- a single staged procedure but requires longer duration and microsurgery set up. Overcoming the disadvantages of distant pedicled flap and free flap. A less morbid and more reliable option is islanded fasciocutaneous flapslateral arm and thoracodorsal perforator flaps [4].

The latissimus dorsi muscle flap has been a workhorse regional pedicled flap for elbow coverage. It has a large arc of rotation and robust pedicle providing coverage of moderate to large soft tissue defects of the elbow, however, beyond the olecranon the latissimus dorsi has a propensity for distal tip necrosis, wound breakdown or failure [5].

Fasciocutaneous flaps on the other hand are thin, reliable, one-stage procedure, and are easily harvested without any subsequent functional impairment since the underlying muscles are left intact (Tolhurst et al., 1983) [6]. The main advantages of the thoracodorsal artery perforator flap are that it contains no muscle, allowing more reconstructive precision, and morbidity is minimised by preserving the function of the latissimus dorsi muscle with a hidden donor site scar. However, meticulous intra-muscular retrograde dissection of the perforator, to the thoracodorsal artery, is necessary in order to obtain suitable pedicle length and vessel diameter.

The parascapular flap is a unique fasciocutaneous flap described for such an indication by Kumar et al. [7]. The parascapular flap was not published in the literature until 1982, dos Santos I credited with the first important anatomical study of the scapular system for the purpose of free tissue transfer [8].

The parascapular flap, based on the circumflex scapular artery, a fasciocutaneous flap can be islanded and tunneled to reach the above elbow stump defect while allowing primary closure of the donor site. The cutaneous branches from the circumflex scapular artery are given off after it emerges from the triangular space bounded by teres minor above, teres major below and the long head of triceps laterally .These are usually two in number; the horizontal branch passes laterally parallel to the spine of the scapula, and the parascapular branch which follows the lateral border of the scapula- 8 to $10 \mathrm{cms}$ long and consistently present.

The cutaneous branches come out between the muscles and spread out at the level of the deep fascia making these the only true fasciocutaneous flaps of the trunk while almost all others are either musculocutaneous or direct cutaneous branches $[9,10]$.

Islanding the flap allows making a more oblique pattern than the conventional vertical flap pattern permitting easier primary closure. Planning it eccentrically allows the flap to reach up to the lower third of the arm comfortably. Ligating the horizontal branch allows a further mobilization of the pedicle by $2-3 \mathrm{cms}$. The donor site can be closed primarily. 
Page 3 of 3

The parascapular flap is a good pedicled flap option for above elbow stump cover- has all advantages of a free flap while avoiding the demerit of long duration of surgery. It is single staged surgery allowing good tissue match, robust cutaneous padding, long pedicle length, primary donor site closure and being muscle sparing (Figure 5).

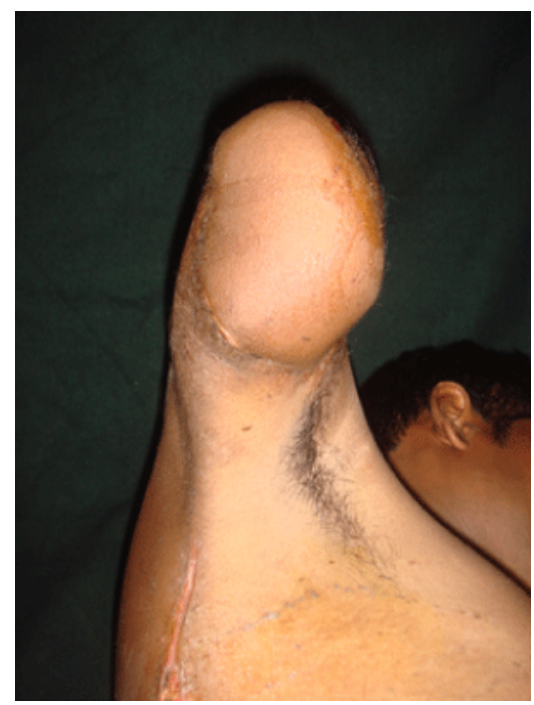

Figure 5: Follow up after 3 weeks shows a well settled flap without any arm movements.
Funding: None

\section{References}

1. Bishop AT (1994) Soft tissue loss about the elbow. Selecting optimal coverage. Hand Clin 10: 531-542.

2. Hur GY, Song WJ, Lee JW, Lee HB, Jung SW, et al. (2012) Elbow reconstruction using island flap for burn patients. Arch Plast Surg 39: $649-654$

3. Choudry UH, Moran SL, Li S, et al. (2007) Soft-tissue coverage of the elbow: an outcome analysis and reconstructive algorithm. Plast Reconstr Surg 119: 1852-7.

4. Jensen M, Moran SL (2008) Soft tissue coverage of the elbow: a reconstructive algorithm. Orthop Clin North Am 39: 251-64.

5. Chen SL, Chen TM, Wang HJ (2004) Free thoracodorsal artery perforator flap in extremity reconstruction: 12 cases. Br J Plast Surg 57: 525-530.

6. Pierce TD, Tomaino MM (2000) Use of the pedicled latissimus muscle flap for upper-extremity reconstruction. J Am Acad Orthop Surg 8: 324-331.

7. Tolhurst DE, Haeseker B, Zeeman RJ (1983) The Development of Fasciocutaneous Flap and its Clinical Application. Plast Reconstr Surg 71: 597-605.

8. Kumar P, Chandra R, Bhatnagar SK, Bhagia SP (1991) Parascapular fasciocutaneous flap for covering an above-elbow amputation stump. Burns 17: 425-426.

9. dos Santos LF (1984) The vascular anatomy and dissection of the free scapular flap. Plast Reconstr Surg 73: 599-604.

10. Cormack GC, Lamberty BG (1983) The anatomical vascular basis of the axillary fascio-cutaneous pedicled flap. Br J Plast Surg 36: 425-427. 